Research

Open Access

\title{
A new integrative weaning index of discontinuation from mechanical ventilation
}

\author{
Sergio N Nemer ${ }^{1}$, Carmen SV Barbas², Jefferson B Caldeira ${ }^{1}$, Thiago C Cárias ${ }^{1}$, \\ Ricardo G Santos ${ }^{1}$, Luiz C Almeida1, Leandro M Azeredo1, Rosângela A Noé3, \\ Bruno S Guimarães ${ }^{1}$ and Paulo C Souza ${ }^{1}$
}

\author{
${ }^{1}$ Critical Care Department, Hospital de Clínicas de Niterói, Rua La Salle 12, Centro, Niterói, Rio de Janeiro, CEP: 24020-090, Brazil \\ 2Pulmonary and Critical Care Department, Hospital das Clínicas de São Paulo, Avenida Dr. Enéas de Carvalho Aguiar, sétimo andar, sala 7079, São \\ Paulo, CEP: 05403-000, Brazil \\ ${ }^{3}$ Biostatistics Department, Universidade Federal do Rio de Janeiro, Gávea, Rio de Janeiro, 22631-180, Brazil \\ Corresponding author: Sergio N Nemer, snnemer@urbi.com.br
}

Received: 24 Mar 2009 Revisions requested: 15 May 2009 Revisions received: 8 Aug 2009 Accepted: 22 Sep 2009 Published: 22 Sep 2009

Critical Care 2009, 13:R152 (doi:10.1186/cc8051)

This article is online at: http://ccforum.com/content/13/5/R152

(c) 2009 Nemer et al.; licensee BioMed Central Ltd.

This is an open access article distributed under the terms of the Creative Commons Attribution License (http://creativecommons.org/licenses/by/2.0), which permits unrestricted use, distribution, and reproduction in any medium, provided the original work is properly cited.

\begin{abstract}
Introduction Indexes predicting weaning outcome are frequently inaccurate. We developed a new integrative weaning index aimed at improving the accuracy of the traditional indexes.

Methods Three hundred and thirty-one patients mechanicallyventilated for more than 24 hours were evaluated. Initially, the threshold values of each index that best discriminate between a successful and an unsuccessful weaning outcome were determined in 115 patients. In the second phase, the predictive performance of these values was tested prospectively in the other 216 patients. Frequency/tidal volume ratio (f/Vt ratio), tidal volume $(\mathrm{Vt})$, tracheal airway occlusion pressure $0.1 \mathrm{~s}(\mathrm{P} 0.1)$, the product of $P 0.1$ and $f / \mathrm{Vt}(\mathrm{P} 0.1 \times f / \mathrm{Vt})$, respiratory rate $(f)$, static compliance of the respiratory system (Cst,rs), ratio of arterial oxygen tension to fraction of inspired oxygen $\left(\mathrm{PaO}_{2} / \mathrm{FiO}_{2}\right.$ ratio) and the new integrative weaning index IWI (Cst,rs $\times$ arterial oxygen saturation/f/Vt ratio) were evaluated in all patients. The readiness for weaning and the decision to return to mechanical ventilation was made by the physician in charge, based on the signs of poor tolerance. The receiver operating characteristic (ROC) curves were calculated in order to evaluate the predictive
\end{abstract}

performance of each index. The Bayes' theorem was used to assess the probability of each test of predicting weaning.

Results In the prospective-validation set, successful weaning was observed in 183 patients (84.7\%) and weaning failure in 33 (15.27\%). IWI presented the highest accuracy, with the area under the ROC curves larger than that under the curves for the $\mathrm{f} / \mathrm{Vt}$ ratio $(0.96 \times 0.85$ respectively; $P=0.003)$, and also larger than that under the curves for the other indexes. IWI presented a higher probability of successful weaning when the test was positive (0.99) and a lower probability when the test was negative (0.14). Measurement of Cst,rs during the weaning process was considered one of the study limitations.

Conclusions IWI was the best predictive performance index of weaning outcome and can be used in the intensive care unit setting.

Trial Registration controlled-trials.com ISRCTN92117906

\footnotetext{
COPD: chronic obstructive pulmonary disease; CROP: acronym of compliance, rate, oxygenation and pressure; Cst,rs: static compliance of the respiratory system; $\mathrm{DA}$ : diagnostic accuracy; $\mathrm{FiO}_{2}$ : fraction of inspired oxygen; f: respiratory rate; $\mathrm{f} / \mathrm{Vt}$ ratio: frequency to tidal volume ratio; ICU: intensive care unit; IWI: integrative weaning index; LR+: likelihood ratio of positive test; LR-: likelihood ratio of negative test; MIP: maximal inspiratory pressure; NPV: negative predictive value; $\mathrm{P} 0.1$ : airway occlusion pressure; $\mathrm{PaCO}_{2}$ : partial pressure of arterial carbon dioxide; $\mathrm{PaO}_{2} / \mathrm{FiO}_{2}$ ratio: ratio of arterial oxygen tension to fraction of inspired oxygen; PEEP: positive end expiratory pressure; PPV: positive predictive value; $P(W+/ T+)$ : probability for weaning success if test is positive; $\mathrm{P}(\mathrm{W}+/ \mathrm{T}-)$ : probability for weaning success if test is negative; $\mathrm{ROC}$ : receiver operator curve; $\mathrm{RSBI}$ : rapid shallow breathing index; $\mathrm{SaO}_{2}$ : arterial oxygen saturation; SBT: spontaneous breathing trial; SE: sensitivity; SP: specificity; Vt: tidal volume.
} 


\section{Introduction}

To date, no weaning predictive index has proven to be ideal [1]. According to the Sixth International Consensus Conference on Intensive Care Medicine [2], patients who meet the following satisfactory criteria should be considered ready for weaning: frequency to tidal volume ratio ( $f / \mathrm{Vt}$ ) less than 105 breaths $/ \mathrm{min} / \mathrm{L}$, respiratory rate $(\mathrm{f})$ of 35 breaths $/ \mathrm{min}$ or less, maximal inspiratory pressure (MIP) of -20 or less to -25 $\mathrm{cmH}_{2} \mathrm{O}$, tidal volume $(\mathrm{Vt})$ more than $5 \mathrm{~mL} / \mathrm{kg}$, vital capacity more than $10 \mathrm{~mL} / \mathrm{kg}$, and arterial oxygen saturation $\left(\mathrm{SaO}_{2}\right)$ above $90 \%$ with a fraction of inspired oxygen $\left(\mathrm{FiO}_{2}\right)$ of 0.4 or less (or partial pressure of arterial oxygen $\left(\mathrm{PaO}_{2}\right) / \mathrm{FiO}_{2}$ ratio of $150 \mathrm{mmHg}$ or above). After the assessment of these indexes regarding readiness for weaning, a spontaneous breathing trial (SBT) should follow as a diagnostic test to determine the likelihood of successful extubation [3].

Weaning decisions based only on expert clinical judgment are not always correct $[4,5]$. Premature discontinuation places severe stress on the respiratory and cardiovascular systems [4], while unnecessary delays can lead to diaphragmatic atrophy [6] that can worsen its force generation and, as a consequence, the MIP. Several predictors of weaning are therefore used to aid decision-making [2].

On reviewing the evidence base for ventilator weaning [7], none of the predictors of weaning demonstrate more than modest accuracy in predicting the weaning outcome. In the McMaster review and guidelines [8,9], 66 predictors of weaning were reviewed and analyzed. Only eight, including the rapid shallow breathing index (RSBI) or the f/Vt ratio, presented significant likelihood ratios to predict the weaning outcome $[8,9]$. The $f / V t$ ratio was evaluated by at least 22 studies $[10,11]$, and can be considered the most used predictor of weaning.

The daily screening of the respiratory function followed by SBTs in selected patients can reduce the time of mechanical ventilation and the cost of intensive care, besides being associated with fewer complications [5]. As many factors can be responsible for weaning failure, we hypothesized that a weaning index that integrates significant physiological weaning parameters could be a better index predictor than the traditional ones [11].

The objective of this study is to test the predictive performance of a new integrative weaning index (IWI). We evaluated two groups of patients. In the first one (training set), the threshold values for each weaning parameter were selected. In the second group, we tested the predictive performance of the selected values in a prospective-validation data set of patients.

\section{Materials and methods}

Three hundred and thirty-one patients who were on mechanical ventilation for more than 24 hours were evaluated. Patients younger than 18 years of age or with neurological and neuromuscular diseases were excluded from the study. The study was conducted from September 2004 to January 2008 in three general intensive care units (ICUs) of the Hospital de Clínicas de Niterói (Rio de Janeiro - Brazil), totaling 27 beds. It was approved by the ethics committees of our institution and registered as an International Standard Randomized Controlled Trial under number 92117906. Informed consent was obtained from each patient, whenever possible, or from the patient's next of kin. The ventilators used were Evita 2 (Dräger, Lübeck, Germany). Discontinuation from mechanical ventilation was attempted when the physician in charge judged that the patient was ready to be weaned, according to the following criteria: the cause for starting mechanical ventilation had resolved or at least improved; body temperature was below $38.5^{\circ} \mathrm{C}$; hemoglobin was equal to or higher than $8 \mathrm{~g} / \mathrm{dl}$; and none or a minimal dose of vasoactive or sedative drugs was administered. $\mathrm{A} \mathrm{PaO}_{2}$ of $60 \mathrm{~mm} \mathrm{Hg}$ or more or $\mathrm{SaO}_{2}$ of $90 \%$ or more with a $\mathrm{FiO}_{2}$ of 0.4 or less and positive end-expiratory pressure (PEEP) of $8 \mathrm{cmH}_{2} \mathrm{O}$ or less were other criteria to be met. A SBT was then evaluated by means of a 2-hour T-piece.

The static compliance of the respiratory system (Cst,rs) was measured in volume control ventilation through the same method used by Aboussouan and colleagues [12], after assessing the digital display of the ventilator to verify the pressure-time curve without inspiratory efforts of the patients. An inspiratory hold for 0.5 to 1.0 second was used to measure the compliance. Cst,rs was calculated by dividing the $\mathrm{Vt}$ by the difference between inspiratory plateau pressure and PEEP. A bedside spirometer (Ohmeda RM 121, Tokyo, Japan) was attached to the expiratory valve of the ventilator in order to check the Vt measurement before each calculation of Cst,rs.

Before the weaning trial, all patients were being ventilated in pressure support ventilation 8 to $10 \mathrm{cmH}_{2} \mathrm{O}$ and PEEP 5 $\mathrm{cmH}_{2} \mathrm{O}$. To measure tracheal airway occlusion pressure $(\mathrm{P}$ 0.1 ), pressure support was reduced to $7 \mathrm{cmH}_{2} \mathrm{O}$ and the $\mathrm{P} 0.1$ value was obtained from the average of three consecutive measurements with intervals of 15 seconds [13,14]. A sample of arterial blood to analyze the $\mathrm{SaO}_{2}$ and the $\mathrm{PaO}_{2} / \mathrm{FiO}_{2}$ ratio was collected in pressure support $7 \mathrm{cmH}_{2} \mathrm{O}$, PEEP $5 \mathrm{cmH}_{2} \mathrm{O}$ and $\mathrm{FiO}_{2}$ 0.35.

During the first minute after discontinuation from mechanical ventilation, spontaneous minute volume and respiratory rate were measured with a bedside spirometer (Ohmeda RM 121, Tokyo, Japan) attached to the airway. The spontaneous Vt was calculated by dividing minute volume by $f$, and the $f / V t$ ratio was calculated by dividing $f$ by $V t$ (in liters) [11]. The indexes were measured by the respiratory physiotherapists before the SBTs. The decision to return to mechanical ventilation was 
made by the physician in charge (who was completely blind to the study and the results of the indexes evaluated), based on the signs of poor tolerance incorporated in our daily routine.

Weaning was considered successful if spontaneous breathing was sustained for more than 48 hours after extubation [2]. During the two-hour period of SBT, tolerance was continuously evaluated by the physician in charge. When the patient remained stable after the two-hour period of SBT, the endotracheal tube was removed. The trial was stopped when at least one of the following poor tolerance criteria was present: $\mathrm{SaO}_{2}$ less than $90 \%$ and $\mathrm{PaO}_{2}$ less than $60 \mathrm{mmHg}$ with $\mathrm{FiO}_{2}$ less than 0.5 or $\mathrm{SaO}_{2}$ less than $88 \%$ and $\mathrm{PaO}_{2}$ less than $55 \mathrm{mmHg}$ with $\mathrm{FiO}_{2}$ less than 0.5 in patients with chronic obstructive pulmonary disease (COPD); partial pressure of arterial carbon dioxide $\left(\mathrm{PaCO}_{2}\right)$ more than $50 \mathrm{mmHg}$ (or increased by 8 $\mathrm{mmHg}$ or more in COPD patients); arterial $\mathrm{pH}$ of 7.33 or less or decreased by 0.07 or more; $f$ more than 38 breaths per minute or increased by $50 \%$ for five minutes or longer; heart rate of more than 140 beats per minute or a sustained increase or decrease in more than $20 \%$; systolic blood pressure of more than $180 \mathrm{mmHg}$ or less than $90 \mathrm{mmHg}$; or in the presence of agitation, diaphoresis, disorientation or depressed mental status. A clearly audible cough and adequate mental status were requirements for patients to be considered ready for extubation [15].

Weaning failure was determined if one of the following criteria occurred: failed SBT; reintubation and/or resumption of ventilatory support within 48 hours following successful extubation; or death within 48 hours following extubation [2]. The distinction between weaning failure (inability to tolerate spontaneous breathing without ventilatory support) and extubation failure (inability to tolerate removal of translaryngeal tube) was taken into account [15], although for results and statistical analysis considerations, all extubation failure patients were also regarded as weaning failure.

\section{The integrative weaning index}

The IWI uses three essential parameters that lend themselves to easy measurement and are independent of the patient's cooperation. The IWI evaluates, in a single equation, the respiratory mechanics, the oxygenation, and the respiratory pattern, through Cst,rs, $\mathrm{SaO}_{2}$ and $\mathrm{f} / \mathrm{Vt}$ ratio respectively.

$$
\mathrm{IWI}=\mathrm{Cst}, \mathrm{rs} \times \mathrm{SaO}_{2} /(\mathrm{f} / \mathrm{Vt})
$$

Several reasons concurred to the choice of the parameters above: $\mathrm{f} / \mathrm{Vt}$ is considered the best [4] or one of the best indexes $[8,16]$ to evaluate the weaning outcome; Cst,rs is associated with a shorter time to weaning when more than 20 $\mathrm{ml} / \mathrm{cmH}_{2} \mathrm{O}$ [12]; and $\mathrm{SaO}_{2}$ has proven to be useful to evaluate the readiness for weaning or to indicate the weaning failure in several studies and revisions [1-3,5]. Multiplying the respiratory compliance by $\mathrm{SaO}_{2}$, we can detect those patients who can or cannot maintain a good oxygenation, despite good or bad respiratory mechanics. Dividing this product by the $f / \mathrm{Vt}$ ratio, we can detect those patients who will or will not be able to maintain unassisted breathing. Cst,rs and $\mathrm{SaO}_{2}$ are generally directly proportional and inversely proportional to f/Vt ratio, as Cst,rs and $\mathrm{SaO}_{2}$ gets higher, f/Vt possibly gets lower. The higher Cst,rs and $\mathrm{SaO}_{2}$, the lower $\mathrm{f} / \mathrm{Vt}$ ratio and IWI tends to be higher.

In order to evaluate the predictive performance of IWI, we compared it with the f/Vt ratio, which has been shown to be the most accurate predictor of failure and success in weaning from mechanical ventilation in the study by Yang and Tobin [11].

We also compared IWI with the following parameters: $\mathrm{PaO}_{2} /$ $\mathrm{FiO}_{2}$ ratio, which represents an important index to evaluate oxygenation; tracheal P 0.1 , which is an estimate of neuromuscular drive and is considered an important indicator of successful weaning, mainly in patients with chronic obstructive pulmonary disease (COPD) [13]; and the product of tracheal $P 0.1$ and $f / V t$ ratio $(P 0.1 \times f / V t)$, which has shown more specificity compared with its components [14,17], f, Vt and Cst,rs.

The study was divided into two sets: the first set was derived from the data concerning 115 patients. In this phase, data were used to select the cut-off value for weaning parameters. The selected values were those that resulted in the fewest false classifications. The second set was derived from the data concerning the other 216 patients.

\section{Statistical analysis}

Continuous variables were presented as mean and standard deviation, categorical variables as frequencies and percentages. Student's $t$ test was used to compare parametric variables and Mann-Whitney test to compare non-parametric ones.

$P$ values less than 0.05 were considered significant. The statistical analysis was performed using SAS software (SAS software package, version 9.0; SAS Institute Inc, Cary, NC, USA).

Sensitivity (SE $=$ true positive/true positive + false negative), specificity ( $\mathrm{SP}=$ true negative/true negative + false positive), positive predictive value (PPV $=$ true positive/true positive + false positive), negative predictive value (NPV = true negative/ true negative + false negative) and diagnostic accuracy (DA) $=$ (true positive + true negative $) /($ true positive + true negative + false positive + false negative) were used to evaluate each index.

The predictive performance of each index was also evaluated by calculating the area under the receiver operator characteristic (ROC) curves $[11,18]$. The area under the ROC curves for each index was calculated by the nonparametric method of Hanley and McNeil [19] and compared through a technique 
developed by the same authors [19]. Classified according to the guideline proposed by Swets [20]: area under the curve of 0.5 is a non-informative result; area under the curve of more than 0.5 and 0.7 or less is less accurate; area under the curve of more than 0.7 and 0.9 or less is moderately accurate; area under the curve of more than 0.9 and less than 1 is highly accurate; and area under the curve of 1 is a perfect test.

In the prospective validation set, the prevalence of weaning success and weaning failure was calculated. The likelihood ratio of a positive test ( $L R+)$ and the likelihood ratio of a negative test (LR-) were calculated for each index. Likelihood ratios between 0.5 and 2.0 indicate that the weaning parameter is associated with small changes in the post-test probability of success or failure. Likelihood ratios from 2 to 5 and from 0.3 to 0.5 correlate with small but potentially important changes in probability, while ratios from 5 to 10 or 0.1 to 0.3 correlate with more clinically important changes in probability. Ratios higher than 10 or lower than 0.1 correlate with very large changes in probability [21].

We used Bayes' theorem to assess the performance of each test in predicting weaning outcome as a function of the prevalence of weaning success or failure in the prospective validation-set [14]. Bayes' theorem allows the calculation of success or failure of weaning after the performance of a test (post-test probability) [21].

\section{Results}

Three hundred and thirty-one patients were evaluated, 115 in a training set and 216 in a prospective-validation set. In the training set and prospective-validation set, successful weaning was observed in $94(81.7 \%)$ and 183 (84.7\%) patients, respectively. In the training set, 17 (81\%) of the 21 weaning failure patients did not tolerate the SBT, while 4 (19\%) completed the SBT, but required reintubation within the following 48 hours after extubation (extubation failure). In the prospective-validation set, $27(82 \%)$ of the 33 weaning failure patients did not tolerate the SBT, while $6(18 \%)$ completed the SBT, but required reintubation within the following 48 hours after extubation (extubation failure). In the total population, weaning failure was observed in 54 of 331 patients (16.35\%, including 10 reintubated patients, 4 of whom died).

Clinical characteristics of the patients in the training set, prospective-validation data set and total population are shown in Table 1 . In the prospective-validation set, the prevalence of weaning success was 0.85 (183/216), and weaning failure was $0.15(33 / 216)$. In the entire study, the prevalence of weaning success was $0.83(277 / 331)$, and weaning failure was $0.16(54 / 331)$.

In training set, the threshold values of each index that best discriminate between successful or unsuccessful weaning were: $\mathrm{PaO}_{2} / \mathrm{FiO}_{2}$ ratio of 255 or more; Cst,rs of $30 \mathrm{ml} / \mathrm{cmH}_{2} \mathrm{O}$ or more; IWI of $25 \mathrm{ml} / \mathrm{cmH}_{2} \mathrm{O}$ breaths/minute/liter or more; $\mathrm{P} 0.1$

Table 1

Clinical characteristics, incidence of successful weaning and weaning failure, and the cause of acute respiratory failure in the training set, prospective-validation data set and in the total population

\begin{tabular}{|c|c|c|c|}
\hline Clinical characteristics & Training set $(n=115)$ & Prospective-validation set $(n=216)$ & Total population $(n=331)$ \\
\hline Age (years) & $64.68 \pm 16.77$ & $63.95 \pm 17.63$ & $64.20 \pm 17.32$ \\
\hline Duration of MV (days) & $9.80 \pm 8.47$ & $8.78 \pm 7.17$ & $9.14 \pm 7.65$ \\
\hline APACHE II & $15.99 \pm 5.80$ & $16.02 \pm 5.43$ & $16.01 \pm 5.55$ \\
\hline Successful weaning, $\mathrm{n}(\%)$ & $94(81.7)$ & $183(84.7)$ & $277(83.68)$ \\
\hline Weaning failure, $\mathrm{n}(\%)$ & $21(18.3)$ & $33(15.3)$ & $54(16.31)$ \\
\hline \multicolumn{4}{|l|}{ Cause of ARF } \\
\hline COPD, n (\%) & 33 (28.69) & $65(30.09)$ & $98(29.6)$ \\
\hline Pneumonia, n (\%) & $25(21.73)$ & $43(19.9)$ & $68(20.54)$ \\
\hline Postoperative ARF, n (\%) & $23(20)$ & $40(18.51)$ & $63(19.03)$ \\
\hline Sepsis, n (\%) & $12(10.43)$ & $27(12.5)$ & 39 (11.78) \\
\hline ARDS/ALI, n (\%) & $8(6.95)$ & $17(7.87)$ & $25(7.55)$ \\
\hline Miscellaneous, n (\%) & $6(5.21)$ & $11(5.09)$ & $17(5.13)$ \\
\hline Multiple trauma, without brain injury, $\mathrm{n}(\%)$ & $4(3.47)$ & 7 (3.24) & $11(3.32)$ \\
\hline Acute pulmonary edema, $\mathrm{n}(\%)$ & $4(3.47)$ & $6(2.77)$ & $10(3.02)$ \\
\hline
\end{tabular}

$\mathrm{ALI}=$ acute lung injury; APACHE $\|=$ Acute Physiology and Chronic Health Evaluation; $\mathrm{ARDS}=$ cute respiratory distress syndrome; $\mathrm{ARF}=$ acute respiratory failure; $\mathrm{COPD}=$ chronic obstructive pulmonary disease; $\mathrm{MV}=$ mechanical ventilation. 
of $3.1 \mathrm{cmH}_{2} \mathrm{O}$ or less; $f$ of 30 breaths/minute or less; $V t$ of 315 $\mathrm{ml}$ or more; $\mathrm{f} / \mathrm{Vt}$ ratio of 100 breaths/minute/liter or less; and $\mathrm{P}$ $0.1 \times \mathrm{f} / \mathrm{Vt}$ ratio of $270 \mathrm{~cm} \mathrm{H}_{2} \mathrm{O} / \mathrm{min} /$ liter or less.

The accuracy, likelihood ratio, probability of weaning success when test is positive and probability of weaning success when test is negative of the indexes utilized to predict the weaning outcome in the prospective-validation data set are shown in Table 2. IWI presented the highest SE (0.97), SP (0.94), PPV (0.99), NPV (0.86), DA (0.97) and likelihood ratio of positive test (16.05) besides the lowest likelihood ratio of negative test (0.03). Moreover, IWI presented the highest probability of weaning success when the test is positive (0.99) and the lowest probability of weaning success when the test is negative (0.14).

The area under the ROC curves for IWI was significantly higher than the corresponding area for the f/Vt ratio $(0.96 \pm$ $0.02 \times 0.85 \pm 0.04$ respectively; $P=0.003$ ) and also significantly higher than the other indexes. The area under the ROC curves for all the indexes are shown in Table 3 and the comparisons among the area under the ROC curves for all the indexes in the prospective-validation data set are shown in Table 4. Selected most significant ROC curves, that is, for IWI, $\mathrm{f} / \mathrm{Vt}$ ratio, Cst,rs and Vt, are shown in Figure 1.

\section{Discussion}

The purpose of weaning indexes is to identify patients who can be successfully weaned. Clinical judgment is not enough to predict weaning outcome accurately $[5,8]$ (50\% PPV and $67 \%$ NPV) $[5,22]$. The search for better indexes or parameters that can best predict weaning outcome has been attempted by most international weaning researchers. SBT were introduced lately showing a positive weaning predictive value of $85 \%$ [5]. However, $15 \%$ of the patients who can complete an SBT require reintubation in the following 48 hours after extubation. This indicates that there are patients that tolerate short SBTs but not longer ones. Although SBT represented an advancement, it is not totally satisfying. In the study by FrutosVivar and colleagues [23], extubation failure occurred in 121 of the 900 patients (13.4\%) that completed the SBT. Among the routinely measured clinical variables, $f / \mathrm{Vt}$ ratio, positive fluid balance 24 hours prior to extubation, and the presence of pneumonia at the beginning of mechanical ventilation were the best predictors of extubation failure [23]. This fact reinforces the hypothesis that not only the clinical evaluation, but also the evaluation of weaning indexes (as the f/Vt ratio) could be helpful.

In our study, $18 \%$ of the patients that completed the SBT were reintubated. Interestingly, our new index IWI predicted extubation failure in 9 out of 10 patients that presented extubation failure. Our results showed that IWI was useful to detect those patients who passed the SBT but needed reintubation afterwards. Further studies are needed to better understand why IWI can detect this population that fails SBT in a late phase. The IWI presented the highest probability of weaning success when the test was positive (0.99) and the lowest probability of weaning success when the test was negative (0.14). The likelihood ratios of positive test and negative test of the IWI were 16.05 and 0.03 respectively, being correlated with great changes in probability [21]. The area under the ROC curves

Table 2

Accuracy, likelihood ratio, probability for weaning success when test is positive and probability for weaning success when test is negative of the indexes used to predict the weaning outcome in the prospective-validation data set

\begin{tabular}{lccccccccc}
\hline Index & $\begin{array}{c}\text { Sensitivity } \\
(\%)\end{array}$ & $\begin{array}{c}\text { Specificity } \\
(\%)\end{array}$ & $\begin{array}{c}\text { Positive } \\
\text { predictive } \\
\text { value (\%) }\end{array}$ & $\begin{array}{c}\text { Negative } \\
\text { predictive } \\
\text { value (\%) }\end{array}$ & $\begin{array}{c}\text { Diagnostic } \\
\text { accuracy (\%) }\end{array}$ & LR+ & LR- & P(W+/T+) & P(W+/T-) \\
\hline $\mathrm{PaO}_{2} / \mathrm{FiO}_{2}$ & 0.60 & 0.67 & 0.91 & 0.23 & 0.61 & 1.79 & 0.61 & 0.91 & 0.77 \\
\hline $\mathrm{Cst}, \mathrm{rs}$ & 0.82 & 0.76 & 0.95 & 0.44 & 0.81 & 3.40 & 0.23 & 0.95 & 0.56 \\
\hline $\mathrm{IWI}$ & 0.97 & 0.94 & 0.99 & 0.86 & 0.97 & 16.05 & 0.03 & 0.99 & 0.14 \\
\hline $\mathrm{P} 0.1$ & 0.76 & 0.70 & 0.93 & 0.35 & 0.75 & 2.52 & 0.34 & 0.93 & 0.65 \\
\hline $\mathrm{f}$ & 0.79 & 0.58 & 0.91 & 0.33 & 0.76 & 1.87 & 0.36 & 0.91 & 0.67 \\
\hline $\mathrm{Vt}$ & 0.76 & 0.73 & 0.94 & 0.36 & 0.76 & 2.81 & 0.32 & 0.94 & 0.64 \\
\hline $\mathrm{f} / \mathrm{Vt} \times \mathrm{P} 0.1$ & 0.76 & 0.73 & 0.94 & 0.36 & 0.76 & 2.81 & 0.32 & 0.94 & 0.64 \\
\hline $\mathrm{f} / \mathrm{Vt}$ & 0.81 & 0.73 & 0.94 & 0.41 & 0.80 & 2.99 & 0.26 & 0.94 & 0.59 \\
\hline
\end{tabular}

Cst, rs $=$ static compliance of the respiratory system; $f=$ respiratory rate; $f / V t$ ratio $=$ frequency to tidal volume ratio; $I W I=$ integrative weaning index; LR+ = likelihood ratio of positive test; LR- = likelihood ratio of negative test; $\mathrm{P} 0.1=$ airway occlusion pressure; $\mathrm{PaO} / \mathrm{FiO}$ ratio $=$ ratio of arterial oxygen tension to fraction of inspired oxygen; $\mathrm{P}(\mathrm{W}+/ \mathrm{T}+)=$ probability for weaning success if test is positive; $\mathrm{P}(\mathrm{W}+/ \mathrm{T}-)=$ probability for weaning success if test is negative; $\mathrm{Vt}=$ tidal volume. 

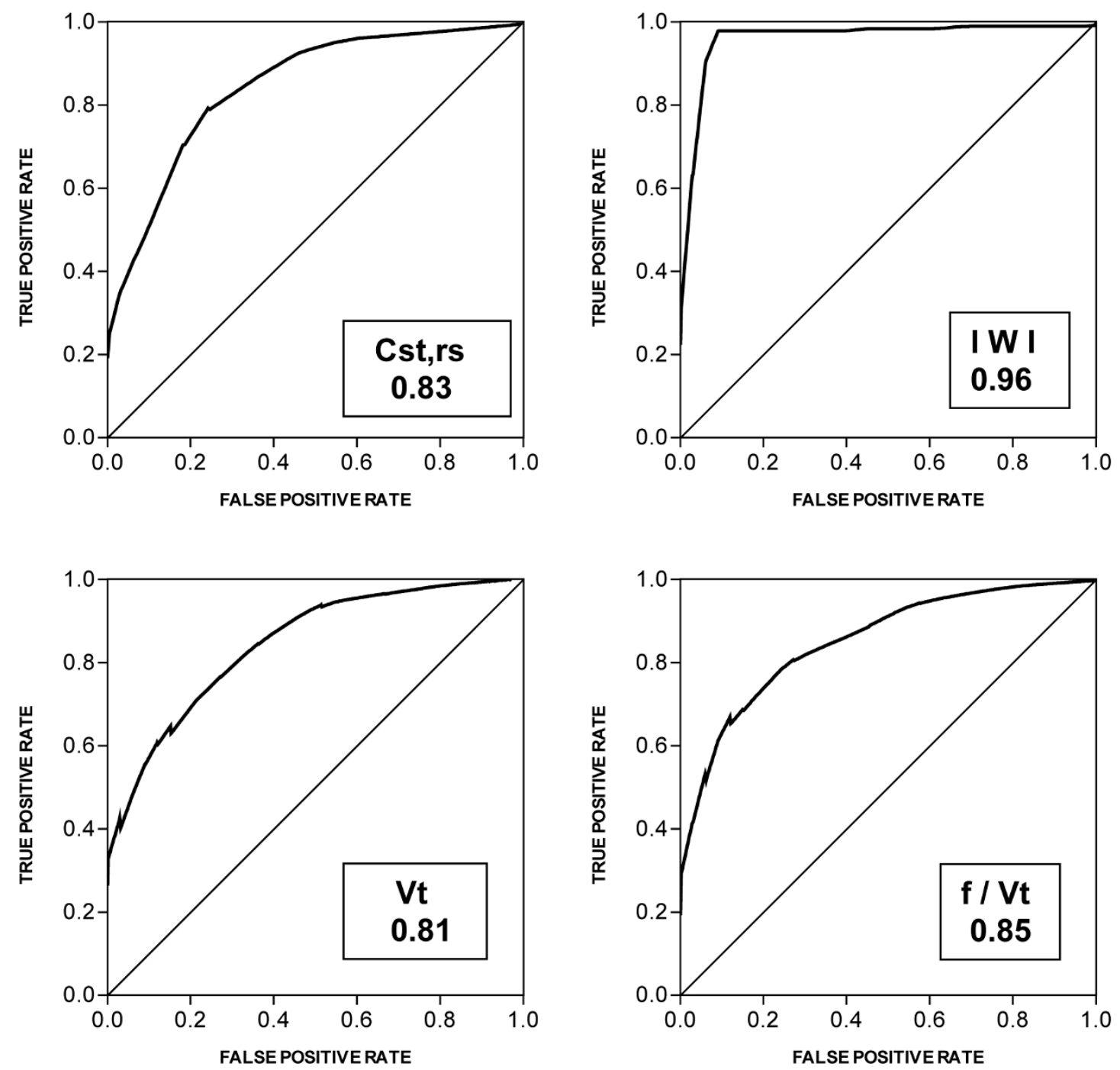

Receiver operator characteristic curves for the indexes evaluated in the prospective validation data set. $f / V t$ ratio $=$ frequency to tidal volume ratio; $\mathrm{IWI}=$ integrative weaning index; $\mathrm{Vt}=$ tidal volume.

for IWI was significantly higher than the area of $f / V t$ ratio $(0.96$ $\pm 0.02 \times 0.85 \pm 0.04$ respectively; $P=0.003$ ), and also significantly higher than the other indexes, being considered highly accurate, according to the guideline proposed by Swets [20].

Some physiological measurements such as MIP, which generally present the area under the ROC curves considered less accurate $[11,21]$, can be helpful when their values are more than -15 to $-10 \mathrm{cmH}_{2} \mathrm{O}$, indicating that the patient probably will not be able to breathe spontaneously for a long time. Weaning indexes that evaluate one single function have generally presented poor accuracy $[8,11]$. For this reason, an integrative index that can evaluate multiple essential functions, such as $\mathrm{f} / \mathrm{Vt}$ ratio and the compliance, rate, oxygenation and pressure (CROP) index [11] have been introduced in the literature. Unfortunately, the CROP index did not present the same accuracy as $f / \mathrm{Vt}$ ratio and its area under the ROC curves was no more than 0.78 [11]. In our study, the new integrative IWI presented the area under the ROC curve of 0.96 and $f / \mathrm{Vt}$ of 0.85. Our hypothesis to justify the difference between the accuracy of CROP index and that of IWI is that in the first one, the MIP (a criterion that is considered to be less accurate) $[11,21]$ was included, and in IWI, f/Vt ratio (an index that is considered to be one of the most accurate) $[11,16]$ was included. We think that MIP inclusion in CROP index impairs its accuracy. 
Table 3

\begin{tabular}{|c|c|}
\hline Index & Area + SE \\
\hline Cst,rs & $0.83 \pm 0.04$ \\
\hline IWI & $0.96 \pm 0.02$ \\
\hline P 0.1 & $0.72 \pm 0.05$ \\
\hline f & $0.73 \pm 0.05$ \\
\hline Vt & $0.81+0.05$ \\
\hline $\mathrm{f} / \mathrm{Vt} \times \mathrm{P} 0.1$ & $0.80+0.05$ \\
\hline $\mathrm{f} / \mathrm{Vt}$ & $0.85+0.04$ \\
\hline $\mathrm{PaO}_{2} / \mathrm{FiO}_{2}$ & $0.65 \pm 0.06$ \\
\hline
\end{tabular}

$\mathrm{f}=$ respiratory rate; $\mathrm{f} / \mathrm{Vt}$ ratio $=$ frequency to tidal volume ratio; $\mathrm{IWI}=$ integrative weaning index; $\mathrm{P} 0.1=$ airway occlusion pressure; $\mathrm{PaO}_{2} /$ $\mathrm{FiO}_{2}$ ratio $=$ ratio of arterial oxygen tension to fraction of inspired oxygen; $\mathrm{SE}=$ standard error; $\mathrm{Vt}=$ tidal volume.

In a prospective study by Aboussouan and colleagues [12] the time to weaning evaluated in 113 consecutive patients was shorter in those that presented the Cst,rs of more than $20 \mathrm{ml} /$ $\mathrm{cmH}_{2} \mathrm{O}$, a normal creatinine level ( 0.6 to $\left.1.4 \mathrm{mg} / \mathrm{dl}\right)$ and a f/Vt ratio of 105 breaths/min/liter or less. Our results corroborated the findings of the study by Aboussouan and colleagues [12], once Cst,rs and f/Vt ratio are included in the IWI equation and presented the second and the third largest areas under the ROC curves ( 0.85 and 0.83 , respectively).

Our results showed that the integration of important single functions into an index such as IWI can be helpful to improve its weaning predictive value when compared with each single function component alone. Patients that present poor prognosis for weaning according to a high $\mathrm{f} / \mathrm{Vt}$ ratio (e.g. 120 breaths/ minute/liter), can present good prognosis according to IWI, if Cst,rs and the $\mathrm{SaO}_{2}$ are higher than $35 \mathrm{ml} / \mathrm{cmH}_{2} \mathrm{O}$ and $90 \%$, respectively. On the other hand, patients with $\mathrm{SaO}_{2}$ less than $92 \%$ and a Cst,rs of $25 \mathrm{ml} / \mathrm{cmH}_{2} \mathrm{O}$ or less, even with a $\mathrm{f} / \mathrm{Vt}$ ratio of 93 breaths/minute/liter, will present poor prognosis for weaning according to the IWI. So, the three components are essential for the accuracy of IWI and the fact that any of the three parameters is not favorable for weaning does not mean that IWI is not going to be favorable, either.

Regarding the evaluation of oxygenation by the IWI index, we preferred $\mathrm{SaO}_{2}$ to $\mathrm{PaO}_{2} / \mathrm{FiO}_{2}$ because $\mathrm{SaO}_{2}$ has fewer variations (generally higher than 90 to $92 \%$ ) $[1,2]$ than $\mathrm{PaO}_{2} / \mathrm{FiO}_{2}$ (higher than 150 to 200) [8,24-26] during the weaning of mechanical ventilation, being a better parameter to compose an accurate IWI. In the study by Khamiees and colleagues [25], most medically ill patients (89\%) with $\mathrm{PaO}_{2} / \mathrm{FiO}_{2}$ ratios from 120 to 200 (four out five patients with $\mathrm{PaO}_{2} / \mathrm{FiO}_{2}$ ratios from 120 to 150), were extubated successfully. Krieger and colleagues [26] found that a $\mathrm{PaO}_{2} / \mathrm{FiO}_{2}$ ratio of 238 had a PPV of $90 \%$ and a NPV of only $10 \%$.

\section{Main limitations of the study}

Although Cst,rs can be measured during discontinuation from mechanical ventilation [11,12,27-29], it is not an easy task to be performed during the weaning process, because the patient's inspiratory effort during the assisted breath could interfere with the inspiratory plateau pressure measurement. In our study we minimized this limitation by observing the digital display of the pressure-time inspiratory plateau curve thus avoiding respiratory cycles that revealed clear inspiratory efforts of the patients.

In our study, the IWI was measured with a fixed $\mathrm{FiO}_{2}$ of $35 \%$ in order to avoid variations in $\mathrm{SaO}_{2}$ due to $\mathrm{FiO}_{2}$ variations. Further studies must be performed to test the IWI accuracy in a wide range of $\mathrm{FiO}_{2}$ values.

The measurement of the tracheal P 0.1 can be a limitation of the study because $P 0.1$ is traditionally measured through an

Table 4

Comparison of the areas under the receiver operator characteristic curves ( $P$ value for the two-tailed test)

\begin{tabular}{|c|c|c|c|c|c|c|c|}
\hline Index & $\mathrm{PaO}_{2} / \mathrm{FiO}_{2}$ & Cst,rs & IWI & P 0.1 & $f$ & Vt & $\mathrm{f} / \mathrm{Vt} \times \mathrm{P} 0.1$ \\
\hline Cst,rs & 0.01 & & & & & & \\
\hline IWI & $<0.0001$ & 0.002 & & & & & \\
\hline P 0.1 & 0.38 & 0.09 & 0.00001 & & & & \\
\hline f & 0.29 & 0.12 & $<0.00001$ & 0.88 & & & \\
\hline Vt & 0.024 & 0.75 & 0.0006 & 0.15 & 0.2 & & \\
\hline $\mathrm{f} / \mathrm{Vt} \times \mathrm{P} 0.1$ & 0.037 & 0.63 & 0.0006 & 0.021 & 0.11 & 0.84 & \\
\hline$f / V t$ & 0.003 & 0.77 & 0.003 & 0.005 & 0.004 & 0.30 & 0.20 \\
\hline
\end{tabular}


esophageal balloon. However, tracheal P 0.1 can be accurately measured at the bedside [30,31] through a new generation of software coupled to microprocessor mechanical ventilators, thus being an easier form of $P 0.1$ assessment than the esophageal balloon technique.

\section{Conclusions}

The use of an index, such as IWI, that integrates important weaning parameters can evaluate the weaning outcome with better accuracy. A satisfactory oxygenation and Cst,rs when associated with an adequate breathing pattern, generally leads to a successful weaning. The opposite generally leads to an unsuccessful weaning. In our study the comparison of IWI to other traditional weaning indexes revealed that IWI was the best index to predict the weaning outcome.

\section{Key messages}

- The $\mathrm{f} / \mathrm{Vt}$ ratio remains one of the best predictors of weaning outcome.

- IWI is an index that comprises respiratory system compliance, which informs about the mechanical condition of the lungs and chest wall; $\mathrm{SaO}_{2}$, which provides information about the patients' capacity to maintain a desirable oxygenation and f/Vt ratio, which informs about the patients' capacity to maintain unassisted breathing, evaluating the weaning outcome with better accuracy.

- IWI was useful to detect those patients who passed the SBT but needed reintubation afterwards.

- In our population, IWI was the best index to predict the weaning outcome.

\section{Competing interests}

The authors declare that they have no competing interests.

\section{Authors' contributions}

All authors, except RN, equally contributed to the design, data acquisition and manuscript preparation. RN (from the Biostatistics Department of Federal University of Rio d Janeiro - Rio de Janeiro - Brazil) wrote the statistical analysis.

\section{Acknowledgements}

The authors are thankful to the respiratory physiotherapists (Cláudia Savedra, Cláudia Cadilhe, Cláudia Geraldo, Juliani Goulart, Léa Ferreira, Lara Tabajaras, Lilian Parizo, Luciene Caldeira, Március Rocha, Lívia Osório, Cátia Coimbra, Eduardo Faria, Jordan Brust, Juliana Dias, Luis Silva, Luis Almeida, Michelle Cabral, Rafael Maia, Rodrigo Ávila, Paulo Reis, Soraya Machado, Monclar Ramalho, Vladimir Nery, Vinícus Nery, Victor Carvalho, Elaine Ávila, Marcelo Andrade and Thiago Clipes) and physicians (especially to Dr. Jorge Isidoro Lain, Dr. João Andrade and Dr. Moyzés Damasceno) of the Intensive Care Unit of the Hospital de Clinicas de Niterói, for their collaboration and dedication in our study.

\section{References}

1. Eskandar N, Apostolakos MJ: Weaning from mechanical ventilation. Crit Care Clin 2007, 23:263-274.
2. Boles J-M, Bion J, Connors A, Marsh B, Melot C, Pearl R, Silverman $\mathrm{H}$, Stanchina $\mathrm{M}$, Vieillard-Baron $A$, Welte $\mathrm{T}$ : Weaning from mechanical ventilation. Eur Respir J 2007, 29:1033-1056.

3. Girard TD, Ely WE: Protocol-driven ventilator weaning: Reviewing the evidence. Clin Chest Med 2008, 29:241-252.

4. Tobin MJ: Advances in mechanical ventilation. $N$ Engl J Med 2001, 344:1986-1996.

5. Ely EW, Baker AM, Dunagan DP, Burke HL, Smith AC, Kelly PT, Johnson MM, Browder RW, Bowton DL, Haponik EF: Effect on the duration of mechanical ventilation of identifying patients capable of breathing spontaneously. N Engl J Med 1996, 335:1864-1869.

6. Levine S, Nguyen T, Taylor N, Frscia ME, Budak MT, Rothenberg $P$, Zhu J, Sachdeva R, Sonnad S, Kaiser LR, Rubinstein NA, Powers SK, Shrager JB: Rapid disuse atrophy of diaphragm fibers in mechanically ventilated humans. N Engl J Med 2008, 358:1327-1335

7. Meade M, Guyatt G, Cook D, Griffith L, Sinuff T, Kergl C, Mancebo J, Esteban A, Epstein SK: Predicting success in weaning from mechanical ventilation. Chest 2001, 120:400S-424S.

8. Maclntyre NR, Cook DJ, Ely WE, Epstein SK, Fink JB, Heffner JE, Hess D, Hubmayer RD, Scheinhorn DJ: Evidence-based guidelines for weaning and discontinuing ventilatory. Chest 2001, 120:375S-395S.

9. Maclntyre NR: Ventilator discontinuing process: evidence and guidelines. Crit Care Med 2008, 36:329-330.

10. Tobin MJ, Jubran A: Meta-analysis under the spotlight: focused on meta-analysis of ventilator weaning. Crit Care Med 2008, 36:1-7.

11. Yang KL, Tobin MJ: A prospective study of indexes predicting the outcome of trials of weaning from mechanical ventilation. N Engl J Med 1991, 324:1445-1450.

12. Aboussouan LS, Lattin CD, Anne VV: Determinants of time-toweaning in a specialized respiratory care unit. Chest 2005, 128:3117-3126.

13. Sassoon CS, Te TT, Mahutte CK, Light RW: Airway occlusion pressure. An important indicator for successful weaning in patients with chronic obstructive pulmonary disease. Am Rev Respir Dis 1987, 135:107-113.

14. Sassoon $\mathrm{CSH}$, Mahutte CK: Airway occlusion pressure and breathing pattern as predictors of weaning outcome. $A m$ Rev Respir Dis 1993, 148:860-866.

15. Epstein SK: Decision to extubate. Intensive Care Med 2002 28:535-546

16. Vassilakopoulos $T$, Zakynthinos $S$, Roussos C: The tension-time index and the frequency/tidal volume ratio are the major pathophysiologic determinants of weaning failure and success. Am J Respir Crit Care Med 1998, 158:378-385.

17. Mérida $A$, Navarrete I, Ruiz $M$, Colmenero $M$ : Técnicas de interrupción del apoyo ventilatorio. In Ventilación Mecánica. Tercera Edición Edited by: Net À, Benito S. Barcelona: Springer-Verlag Ibérica; 1998:187-202.

18. Metz CE: Basic principle of ROC analysis. Semin Nucl Med 1978, 8:283-298

19. Hanley JA, McNeil BJ: A method of comparing the areas under receiver operating characteristic curves derived from the same cases. Radiology 1983, 148:839-843.

20. Swets JA: Measuring the accuracy of diagnostic systems. Science 1988, 240:1285-1293.

21. Conti G, Montini L, Pennisi MA, Cavaliere F, Arcangeli A, Bocci MG, Proietti R, Antonelli M: A prospective, blinded evaluation of indexes proposed to predcit weaning from mechanical ventilation. Intensive Care Med 2004, 30:830-836.

22. Stroetz RW, Hubmayr RD: Tidal volume maintenance during weaning with pressure support. Am J Respir Crit Care Med 1995, 152:1034-1040.

23. Frutos-Vivar, Ferguson ND, Esteban A, Epstein SK, Arabi Y, Apezteguía C, González M, Hill NS, Nava S, D'Empaire G: Risk factors for extubation failure in patients following a successful spontaneous breathing trial. Chest 2006, 130:1664-1671.

24. Bernard G, Artigas A, Brigham K, Carlet J, Falke K, Hudson L, Lamy $M$, Legall J, Morris A, Spragg R: The American-European consensus conference on ARDS: definitions, mechanisms, relevant outcomes and clinical trial coordination. Am J Respir Crit Care Med 1994, 149:818-824.

25. Khamiees $M$, Raju $P$ DeGirolamo A Amoateng-Adjepong $Y$, Manthous CA: Predictors of extubation outcome in patients who 
have successfully completed a spontaneous breathing trial. Chest 2001, 120:1262-1270.

26. Krieger BP, Ershowsky PF, Becker DA, Gazeroglu HB: Evaluation of conventional criteria for predicting successful weaning from mechanical ventilatory support in elderly patients. Crit Care Med 1989, 17:858-861.

27. Gluck EH, Curgian L: Predicting eventual success or failure to wean in patients receiving long-term mechanical ventilation. Chest 1996, 110:1018-1024.

28. Epstein SK: Weaning parameters. Respir Care Clin N Am 2000, 6:253-301.

29. Manthous CA, Schmidt GA, Hall JB: Liberation from mechanical ventilation: a decade of progress. Chest 1998, 114:886-901.

30. Laghi F: Assessment of respiratory output in mechanically ventilated patients. Respir Care Clin N Am 2005, 11:173-199.

31. Kuhlen R, Hausmann S, Pappert D, Slama K, Rossaint R, Falke K: A new method for $P 0.1$ measurement using standard respiratory equipment. Intensive Care Med 1995, 21:554-560. 